\title{
Dishonesty and grants
}

Leigh Van Valen, Professor of Biology at the University of Chicago, is Editor of the journal Evolutionary Theory and is well known for his criticisms of "irresponsible" scientific publishing. Here he comments on an aspect of the American grant system which is also damaging to scientific research

VARIOUS defects of the system of research grants, as it is practised in the United States, have been discussed extensively. I wish to focus on one which is rarely mentioned, although widely known, and which may well be the most serious. This is the incompatibility, in practice, between honest grant applications and conceptually original work.

The incompatibility is as follows. Any conceptually innovative scientist with some experience knows that there is a good probability that in the next year or two he will have one or more new ideas which will change the direction of his research. In practice, the National Science Foundation and the National Institutes of Health do not tolerate much deviation from the plan of research in the original proposal. The scientist must therefore either adhere to the original proposal at a loss to science, or do his best science while deviating from the conditions under which his grant was awarded.

\section{Two alternatives}

Most scientists resolve the situation in one of two ways at the time of applying for grants:

- Original workers who do participate in the granting process use various conscious or unconscious deceits. One kind is a proposal to do research which has just been done or will be done before the grant arrives. This is very common (M. L. Wolbarsht, Science, 185, 399; 1974). Another common kind is a proposal to do research which will be done only if no new ideas come before the grant ends. For both these ploys, and others, it is empirically necessary that the nature of the ploy not be stated. This is what creates the dishonesty. When the granting agency explicitly knows of such reservations, or if the application is general enough to be honest, the application is automatically rejected. This is of course the same mentality that required J. D. Watson to falsify his NSF-administered postdoctoral fellowship, where he did part of his Nobel Prize work that he couldn't have done if he had acted honestly.

- Research which really is predictable, at least in outline, is common and is the backbone of most scientists most of the time. There is no problem in such cases. One really can know that one will probably be able to work out the evolution of a group, or test an established hypothesis, or determine whether a known phenomenon applies in a particular case. Because the work is predictable, even though the results may not be, it is usually less than intellectually exciting. It may nevertheless have important results, and it really is necessary for the progress of science. Being easily accountable, it gets funded. Exciting work by honest people does not get funded. This may perhaps take its place among the laws of nature, at least within the boundaries of the United States.

Why should the subject of a grant be adhered to when science is better served by deviation? The administrative answer is accountability: a grant is given for a specific purpose. In applied science this is certainly appropriate. Here the purpose of the money is determined by governmental priorities, by the government's view of national (and occasionally even human) needs, In pure science, however, the aim of giving the money is the advance of scientific knowledge. It is this very advance which is hindered by the present practice. A diversity of approaches is valuable but is not permitted.

The heart of science is new ideas, and their development is discriminated against. This is not true in Europe, whatever the defects of the systems there. My European visitors, who have come from every major country, are uniformly astonished that the United States Government refuses to support creative science. The problem is as real for Szent-Györgyi (Science, 176,
966; 1972), with a Nobel Prize to back him up, as it is for others. I have had several useful ideas in biology and mathematics. None were developed under a government grant, and none could have been. I have also had several grants and eventually realised that the required conformity stultified my research.

\section{Three categories}

What to do? I suggest that there be three categories of grants:

- Most grants would be based on specific proposals, as now, but with the explicit understanding that new ideas may be followed at the scientist's discretion. Specific restrictions on such freedom may be necessary in rare cases.

- Specific proposals are inappropriate for much theoretical work; when one knows just what one will do, it is done. This is quite literally true. In such cases grants could be awarded on the basis of research done in the past three years or so, with allowance for extenuating circumstances. The second category would also be appropriate for some scientists who are beginning to work in an area different from their previous work.

- For beginning theoreticians, a modest amount of money for computer costs and the like could be provided for a year or two. These three proposals aim to minimise waste of money while endeavouring to maximise the progress of science.

Many scientists are perfectly comfortable with the present situation. Some of them are the Appollonians of Szent-Györgyi, who "develop established lines to perfection". Others are Dionysians, who know "only the direction in which [they want] to go into the unknown", but who have reconciled their dishonesty with survival. For it is often a matter of survival. Rationalisation of dishonesty is therefore easy.

We recently removed a President because he was dishonest. The norm in our science remains dishonesty, because it is made necessary for the survival of creative research. Often one may be honest or continue in science, but not both. The choice applies mainly to the more creative scientists. We can easily resolve the dilemma if we so want. Do we? 